\title{
A força de trabalho no complexo da saúde: vantagens e desafios
}

\author{
The workforce in the Brazilian healthcare grid: \\ advantages and challenges
}

Claudio Salvadori Dedecca ${ }^{1}$

Cassiano José Bezerra Marques Trovão ${ }^{1}$

\footnotetext{
${ }^{1}$ Instituto de Economia, Unicamp. Caixa Postal 6135. 13083-970 Campinas SP claudio.dedecca@ eco.unicamp.br
}

\begin{abstract}
This essay discusses the importance and the dimension of the workforce in the healthcare grid in the Brazilian labor market. It examines the growing occupation trend in relation to restrictions to the rise in productivity, especially in the activities in the center of the healthcare complex. In a context of recurrent governmental budget constraints, the development of the Unified Health System ultimately results in increased coverage, but with deteriorating conditions and wages. This trend has also been accompanied by tensions in resource sharing with other pillars of social policies. The essay concludes that, in order to achieve high quality treatment and adequate working conditions, public health policy requires a better solution for its funding and greater linkages with the institutional matrix of general social policies. Even with the need for greater efficiency in spending, current resources are insufficient. Furthermore, it is important to highlight the need for institutional interaction of health policy with other social policies, seeking to ensure a more comprehensive and quality service for the population.
\end{abstract}

Key words Primary healthcare services, Labor market, Health personnel, Human resources in health, Health occupations, Training
Resumo Este ensaio aborda a importância e a dimensão da força de trabalho do complexo da saúde para o mercado de trabalho brasileiro. Explora a tendência de crescimento da ocupação em face das restrições para o aumento de sua produtividade, especialmente nas atividades do núcleo desse complexo. Em um contexto de recorrente restrição orçamentária do Estado, o desenvolvimento do Sistema Único de Saúde acaba por resultar em um aumento da cobertura, porém, com deterioração das condições e da remuneração da força de trabalho vinculadas às atividades nucleares do complexo da saúde. Esse movimento tem sido acompanhado por tensões na partilha dos recursos com os demais pilares da politica social. O ensaio conclui que, para se alcançar qualidade de atendimento e condições adequadas de trabalho, a política pública de saúde demanda o equacionamento adequado de seu financiamento e uma maior articulação com a matriz institucional da política social mais geral. Mesmo admitindo-se a necessidade de maior eficiência do gasto, os recursos existentes são insuficientes. Além disso, é apontada a necessidade institucional de articulação da política de saúde com as demais políticas sociais visando dar uma atenção mais abrangente e de qualidade à população.

Palavras-chave Serviços básicos de saúde, Mercado de trabalho, Pessoal de saúde, Recursos humanos em saúde, Ocupações em saúde, Capacitação 


\section{Introdução}

Tem sido crescente o esforço de análise da questão do trabalho no complexo da saúde do Brasil nos últimos 20 anos. A criação do Sistema Único de Saúde (SUS) a partir das determinações da Constituição Federal de 1988, que estabeleceu o direito universal de acesso ao atendimento de saúde, causou a ampliação da política pública, tanto em termos de cobertura da população, quanto de seus gastos correntes em investimentos e em pessoal. Ademais, a consolidação do SUS estimulou o crescimento de diversos segmentos industriais $\mathrm{e}$ de serviços, como é o caso da transformação recente da indústria de fármacos, decorrente do programa de medicamentos genéricos.

Reconhece-se que o SUS permitiu um maior acesso à saúde pela população brasileira; no entanto, os serviços prestados são, em média, de baixa qualidade. Este resultado esteve e está intimamente relacionado à universalização do acesso em um contexto de significativa restrição orçamentária vivida pela política de saúde, seja em razão da ausência de vinculação orçamentária de recursos adequados à sua necessidade, seja em razão da crise fiscal vivida pelo Estado brasileiro. Tal quadro decorreu do longo período de estagnação da economia brasileira nos anos 1980, 1990 e nos primeiros anos da década passada.

Em 2000, buscou-se equacionar o financiamento da política pública de saúde com a aprovação da Emenda Constitucional n. ${ }^{\circ} 29^{1}$, que definiu obrigações dos entes federativos para com a política de saúde. A regulamentação da EC n. ${ }^{\circ} 29 /$ 2000 ficou pendente até o final de 2011, devido à ausência de um maior interesse em se resolver esse problema por parte do Congresso e à resistência dos governos federal e subnacionais. Medidas paliativas de financiamento foram adotadas ao longo das décadas de 1990 e 2000, como a Contribuição Provisória sobre Movimentação ou Transmissão de Valores e de Créditos e Direitos de Natureza Financeira (CPMF) ${ }^{2}$, sem que uma solução estável e estrutural fosse encaminhada. A aprovação tardia da regulamentação não resultou no equacionamento das necessidades de recursos para a política pública de saúde, em razão da recusa da União em comprometer 10\% de sua receita corrente com a política e em estabelecer uma fonte específica de financiamento.

Em suma, pode-se afirmar que o valor per capita gasto pela política pública continuará sendo extremamente baixo, mesmo quando incorporados os recursos garantidos pela aprovação da EC n. ${ }^{2}$ 29/2000. A insuficiência de recursos explicita-se, ainda mais, ao se comparar os gastos no Brasil com aqueles realizados por países que mantêm políticas de saúde de cobertura universal ${ }^{3}$.

Em razão das limitações significativas encontradas pelo SUS em seu processo de consolidação nos últimos 20 anos, a política pública de saúde conviveu com a contínua expansão do sistema complementar privado ${ }^{4}$. Este movimento esteve estreitamente relacionado à tendência mundial de progressiva dominância do sistema complementar pelas instituições financeiras, em razão das elevadas oportunidades de ganho que os planos coletivos e individuais podem propiciar.

Qualquer avaliação mais abrangente da evolução recente da política pública de saúde evidencia que ela carrega uma complexidade institucional crescente, com articulações também complexas entre seus diversos segmentos ${ }^{5-7}$. Este processo tem exigido um esforço expressivo do Estado Nacional na regulação e regulamentação das diversas atividades, programas e ações conduzidas pela política pública, nas esferas estatal e privada.

A questão do trabalho constitui-se em uma das dimensões relevantes que essa complexidade institucional carrega. Como será explorada neste ensaio, a expansão dos serviços de atendimento à saúde traduz-se em uma elevada elasticidade de geração de novas oportunidades ocupacionais, devido à centralidade do trabalho em segmentos importantes que caracterizam o complexo. Em decorrência, ele tende a apresentar um incremento lento da produtividade ${ }^{8}$, ao contrário do observado em outros setores da atividade econômica. Tanto em razão das determinações constitucionais que induziram uma ampliação do atendimento público à saúde, quanto às especificidades decorrentes do próprio complexo, constata-se que este apresenta um elevado peso em termos ocupacionais, inferior somente ao observado para os complexos produtivos da construção civil e da educação. O complexo da saúde, portanto, tende conviver com uma expansão expressiva e recorrente de seu nível ocupacional, independentemente da conjuntura econômica ${ }^{9,10}$.

A tendência inerente de crescimento do emprego provocada pela expansão da cobertura e pela diversificação e ampliação da cesta de serviços, reforçada ainda pelo envelhecimento da população, em uma situação orçamentária marcada pela insuficiência de recursos, tem se traduzido na deterioração dos contratos e das relações de trabalho no complexo da saúde.

É parte das dificuldades do atendimento universal à saúde o acesso a recursos financeiros suficientes para a contemplação de sua complexida- 
de. Essa situação provoca, de um lado, uma expansão da cobertura com o comprometimento da sua qualidade e, de outro, uma crescente tensão com as demais políticas sociais. Isso se traduz em um sistemático canibalismo de recursos, já escassos, que estas têm disponível. Neste sentido, a deterioração dos contratos, das relações de trabalho e da qualidade do serviço prestado no complexo da saúde não pode ser enfrentada sem que sejam considerados os problemas decorrentes do arranjo institucional da política social, nem mesmo sem que se defina uma estratégia comum que envolva a proteção social como um todo.

O ensaio, portanto, explora as questões inicialmente apontadas nesta introdução a partir de uma perspectiva do trabalho no complexo da saúde. Ele está estruturado em cinco sessões e em algumas observações finais. Inicialmente se analisa a configuração do complexo da saúde e do trabalho visando mostrar a especificidade desta relação. Em seguida explora-se o trabalho na atividade fim do complexo, isto é, sua estrutura no atendimento à saúde da população. A questão da qualificação e da remuneração são os temas tratados na sequência. O percurso analítico permite finalmente elucidar a tendência de deterioração das condições de trabalho no setor, apesar de suas vantagens frente ao mercado de trabalho como um todo ${ }^{11,12}$.

\section{As relações entre a configuração do complexo da saúde e o trabalho}

É possível pensar o complexo da saúde em dois segmentos básicos de atividade: $\boldsymbol{o}$ núcleoconfigurado pelas atividades de atendimento direto à saúde da população, isto é, hospitais, postos de saúde, clínicas e laboratórios; e o complementar - estruturado nas atividades de produção de fármacos, farmácias, produção de equipamentos médicos, produção de insumos, lavanderia industrial, entre outros setores da atividade econômica. Do ponto de vista da ocupação é possível estabelecer a seguinte segmentação: núcleoorganizado pelas ocupações típicas de atendimento à saúde, como aquelas de médico, enfermeiro, dentista e terapeuta; afins - que contempla as ocupações de nutricionistas, assistentes sociais, operadores de equipamentos, biologista e ópticos; e complementar - configurado por ocupações nas atividades não diretamente vinculadas ao atendimento de saúde propriamente dito.

Os segmentos de atividades e de ocupações complementares tendem a ser organizados segundo uma regulação e uma regulamentação de natureza mais geral, isto é, estabelecida tanto para a atividade produtiva como para o mercado de trabalho. Quanto aos segmentos das atividades e ocupações nucleares e afins, observa-se a preponderância de regulações e regulamentações públicas específicas. $\mathrm{Na}$ experiência brasileira, tanto o Ministério da Saúde quanto os Conselhos Profissionais ordenam o exercício das profissões associadas às ocupações nucleares e parte das afins. São exemplos disso, a Lei n. ${ }^{\circ} 8080 / 90^{13}$ e a NOB/RH-SUS de $2002^{14}$. A experiência internacional tem mostrado crescente regulação pública dessas ocupações.

A segmentação da organização produtiva e da estrutura ocupacional evidencia a extensão das atividades direta ou indiretamente vinculadas ao atendimento da população, apresentando o motivo de elas serem consideradas enquanto complexo da saúde. A atividade nuclear de atendimento à saúde tem a capacidade ou a necessidade de mobilizar um conjunto relativamente grande de atividades, impedindo que a definição, a implantação e a gestão dos programas e das ações possam assumir uma perspectiva restrita à função direta.

As iniciativas de vacinação ou de exame de sangue para análise de diabetes, por exemplo, exigem que se mobilize o setor responsável para produção dos insumos necessários. Necessitam, também, que sejam mobilizadas estruturas física e de pessoal com capacidade específica para as ações. Diversos outros exemplos poderiam ser dados de programas ou ações da política de saúde que demandam o envolvimento de uma diversidade de atividades que apenas parcialmente estão diretamente a ela associadas.

De acordo com o Instituto Brasileiro de Geografia e Estatística (IBGE), o consumo de bens e serviços da saúde representava $8,7 \%$ do Produto Interno Bruto de 2007 e, segundo a Organização para a Cooperação e Desenvolvimento Econômico (OCDE) $)^{15}$, os países desenvolvidos tinham um gasto com saúde ao redor de 11,0\% em 2009. Levando-se em conta a metodologia adotada, tais indicadores podem ser considerados como referências básicas para qualificar a importância do setor. Infelizmente, não são detalhadas, nas informações do PIB, as contribuições dos diversos setores produtivos direta ou indiretamente envolvidos com o atendimento à saúde. É muito provável que, caso disponível, este indicador apontasse uma participação maior do complexo, em razão de as informações de despesa serem calculadas, principalmente, a partir do consumo final. 
A complexidade da estrutura produtiva relacionada à política de saúde reflete uma também complexa estrutura ocupacional, levando a que esta apresente uma dimensão expressiva para a configuração do mercado de trabalho. Segundo avaliação da OCDE, a participação da ocupação do complexo da saúde cresceu de $8,5 \%$ para 10,1\% nos países desenvolvidos entre 1965 e 2009. Tal movimento também tem sido observado no Brasil. A participação da ocupação do complexo da saúde teve um aumento de $4,4 \%$ para $4,8 \%$ entre 2003 e 2009.

Este resultado se mostra ainda mais expressivo quando se compara a dimensão da ocupação do complexo da saúde com aquela de outros considerados importantes no mercado de trabalho brasileiro. A partir das informações da Tabela 1, podemos constatar que o complexo da saúde apresenta-se como a terceira estrutura ocupacional do mercado de trabalho não agrícola brasileiro, inferior somente aos setores da Construção Civil e da Educação. Note-se que ela é significativamente superior à estrutura vinculada a um complexo considerado de grande importância no mercado de trabalho nacional, o metal mecânico/ material de transporte. Os resultados revelam ainda a contribuição das atividades complementares para a geração de postos de trabalho no complexo, representando cerca de 50\% em 2009.

Ao se considerar o incremento da ocupação e o grau de formalização das relações de trabalho no complexo da saúde, os resultados são ainda mais expressivos. Em termos globais, o incremento da ocupação foi um dos mais elevados dentre os setores observados. Esse movimento reflete-se com mais intensidade no incremento da ocupação de atividades nucleares, que foi da ordem de $33 \%$ entre 2003 e 2009 . Ademais, evidencia-se que o complexo da saúde apresenta um dos mais elevados níveis de formalização das relações de trabalho, situando-se ao redor de $88 \%$ para o total da estrutura ocupacional e de $90 \%$ para as atividades nucleares.

\section{A organização da atividade de atendimento e o trabalho}

A mensuração da ocupação do complexo da saúde mostra, por um lado, sua importância para o mercado de trabalho brasileiro, mas, por outro, evidencia uma preocupação, em razão da pressão que o crescimento desse complexo gera em termos de recursos financeiros. Tal preocupação torna-se ainda mais evidente quando se considera a perspectiva de uma demanda crescente pelo atendimento de saúde decorrente do envelhecimento da população e da elevação de sua expectativa de vida.

No Brasil, esse problema se mostra ainda mais explicito devido à existência de uma política de saúde universal que apresenta, em média, qualidade de atendimento insatisfatória além de deficiência em termos de cobertura. A determinação constitucional, a partir do final dos anos 1980, tem exigido do Estado a progressiva ampliação da proteção social que, frente às restrições orçamentárias impostas pelo período de estagnação ou de baixo crescimento, tem se realizado com

Tabela 1. Indicadores básicos de população ocupadas segundo complexos de atividades econômicas - Brasil 2009

\begin{tabular}{lccccc}
\hline & \multicolumn{2}{c}{ Ocupação } & $\mathbf{2 0 0 9}$ & Incremento total & $\begin{array}{c}\text { Índice de } \\
\text { formalização }\end{array}$ \\
\cline { 2 - 3 } & Absoluto & Relativo & 2008-2009 & 88,5 \\
\hline Complexo Saúde & 4.472 .086 & 4,8 & 26,8 & 90,2 \\
Saúde Núcleo & 2.425 .856 & 2,6 & 33,6 & 53,5 \\
Total & & & & 16,6 \\
$\quad$ Agrícola & 92.689 .253 & 100,0 & 15,7 & 61,1 \\
Não agrícula & 15.714 .721 & 17,0 & $-5,6$ & 84,7 \\
$\quad$ Metal mecânico/material transporte & 76.974 .532 & 89,0 & 21,2 & 89,7 \\
$\quad$ Químico (inclusive petróleo) & 3.487 .169 & 3,8 & 28,9 & 86,9 \\
$\quad$ Financeiro & 1.221 .243 & 1,3 & 12,3 & 36,7 \\
$\quad$ Construção civil & 1.131 .833 & 1,2 & 11,0 & 87,8 \\
$\quad$ Educação & 6.894 .479 & 7,4 & 32,2 & \\
& 5.239 .075 & 5,7 & & 20,4 &
\end{tabular}

Fonte: Pesquisa Nacional por Amostra Domiciliar, PNAD/IBGE. Microdados. Elaboração própria. 
um padrão de qualidade insuficiente, tanto no serviço oferecido quanto nas relações de trabalho $^{7,10,16}$.

Para entender as restrições que a política de saúde apresenta no campo da estrutura ocupacional é necessário explicitar duas questões referentes à sua inserção na matriz institucional da política social e à estruturação do próprio atendimento à saúde em uma perspectiva de universalidade.

A Constituição Federal de 1988, chamada de Constituição Cidadã em razão da importância dada à política social em suas determinações, adotou na maioria das vezes uma perspectiva universal em termos de proteção social. Nela encontra-se estabelecido, enquanto direito, o acesso à educação, saúde, renda, trabalho e habitação. Desde o início dos anos 1990, os governos estaduais e municipais têm sido induzidos a assumirem crescentes responsabilidades em termos de financiamento e execução das políticas sociais, apesar da recorrente restrição orçamentária que sobre eles recai. Muitas vezes, o sistema judiciário tem adotado iniciativas visando obrigar os Governos a respeitarem as determinações constitucionais. Mesmo considerando-se justo e socialmente ético que o Estado cumpra tais determinações constitucionais, esse processo tem se traduzido em uma sistemática disputa por recursos entre as políticas sociais, expressa muitas vezes pela defesa de uma política específica ${ }^{17}$.

Considerando a matriz institucional, é impossível pensar a política de saúde independentemente da política social. Superar seus estrangulamentos exige, tanto em termos orçamentários quanto em gestão, que a política de saúde seja devidamente articulada às demais vertentes da política social. Esta exigência fica ainda mais explícita quando analisada a conformação institucional da própria política de saúde.

Seguindo experiências internacionais exitosas de natureza universal, tem se procurado estruturar a política de saúde a partir das formas de atendimento de baixa, média e alta complexidade. Esta estratégia visa filtrar a demanda indevida para as unidades de serviços de alta complexidade, bem como ampliar o atendimento de caráter preventivo, visando melhorar a qualidade de vida da população e, consequentemente, reduzir a demanda futura por procedimentos de custo elevado.

$\mathrm{O}$ atendimento primário de baixa complexidade visa resolver problemas mais simples e fazer a prevenção de modo geral. Esse pilar de menor complexidade demanda poucos equipamentos e muitos recursos humanos, estando focado principalmente na prevenção de doenças e/ou de acompanhamento do estado geral de saúde da população. A expansão da cobertura do serviço à população é caracterizada por uma elevada elasticidade do emprego. Desde 1988, a progressiva universalização da cobertura do SUS, marcada pela posterior adoção do Programa Saúde da Família (PSF), requer uma ampliação sistemática do volume de recursos humanos (emprego), ainda que tal processo ocorra pari passu a uma progressiva deterioração das condições de trabalho e da remuneração dos profissionais envolvidos.

Quanto aos pilares de média e alta complexidade, os investimentos em equipamentos e infraestrutura tendem a ser, progressivamente, mais expressivos que aqueles em recursos humanos. A maior participação do setor privado encontra-se naqueles de média complexidade. Quanto ao de alta complexidade, o setor privado tem expressão, mas é o setor público que direta ou indiretamente responde por parte relevante dos investimentos e mesmo pela remuneração de serviços prestados.

A dinâmica diferenciada de cada um desses pilares em termos de investimentos em equipamentos, em infraestrutura e em recursos humanos gera demanda também diferenciada junto aos segmentos produtivos de fármacos e de equipamentos, com impactos importantes na balança comercial pela via das importações. Nesse sentido, aparecem como fundamentais as ações das políticas industrial e de ciência, tecnologia e inovação para ampliar a autonomia nacional em termos de necessidades de equipamentos, insumos e fármacos, oriundas da política de saúde, além de garantir a qualificação dos recursos humanos nas mais diversas áreas de atendimento.

Considerando a dinâmica demográfica de envelhecimento da população, existe uma tendência de ampliação das pressões sobre todos os pilares, bem como a emergência de novas modalidades de serviços como o atendimento de saúde domiciliar ao idoso. Portanto, ao contrário de outros setores de atividade econômica, a experiência internacional mostrou que o aumento da cobertura e do gasto da política de saúde apresenta ganhos muito limitados em termos de produtividade. É elevada a elasticidade do gasto com o aumento da cobertura e com a diversificação das modalidades de atendimento. Decisões visando fomentar as diversas modalidades de atendimento e adequar a cobertura dos serviços de baixa complexidade para melhorar o bem-estar da população e a prevenção de doenças, além de es- 
tratégias como aquela do PSF, tendem a produzir uma ampliação expressiva das necessidades de recursos humanos. A política de saúde talvez constitua a única situação em que o aumento do uso de equipamentos concorre pouco com a necessidade de maiores e melhores recursos humanos ${ }^{7}$.

Além disso, iniciativas de natureza semelhante ao PSF são comuns a outras áreas da política social, o que requer a articulação e mesmo a racionalização entre elas. Em suma, existe a necessidade de se considerar tanto as implicações da institucionalidade interna da política de saúde quanto àquelas advindas das demais políticas sociais, de forma a romper o efeito negativo que se estabelece na disputa por recursos.

Ter presente essas características da política é decisivo para se pensar uma agenda para o SUS. Considerada sua estrutura institucional atual, para tornar esse sistema socialmente justo e utilizá-lo como um instrumento relevante para melhorar a condição de cidadania da população brasileira, faz-se necessário resolver o financiamento da demanda crescente em volume e qualidade de investimentos em recursos humanos, em infraestrutura e em equipamentos. Defende-se que para isso haja uma solução mais global para o financiamento da política social.

No que diz respeito aos recursos humanos próprios da política de saúde, considerados neste ensaio como o núcleo da estrutura ocupacional do complexo, resultados positivos para sua estruturação exigem que se resolvam os graves problemas de heterogeneidade de formas de contratos e de relações de trabalho e de remuneração ${ }^{11}$.

\section{A regulação das profissões \\ e a centralidade do trabalho}

A análise anterior explicita a particularidade da relação entre a ampliação do atendimento à saúde da população e a geração de empregos. A perspectiva de elevada elasticidade desta relação justifica uma diferenciação do complexo da saúde, quando comparado a outros complexos ou setores da atividade econômica. O trabalho exerce uma centralidade na organização produtiva do complexo, sendo extremamente relevante para a qualidade do serviço prestado à população.

Entretanto, a centralidade do trabalho, em especial nas suas atividades nucleares, decorre também de outras especificidades do complexo da saúde. Uma delas associa-se a irreversibilidade de procedimentos com resultados que não atendem ao esperado e que podem ter consequências negativas e definitivas para o paciente. Isto é, como em toda atividade, o atendimento à saúde incorpora riscos, sendo que, ao contrário de outros setores, suas consequências podem não ser passíveis de reversão.

Por este motivo, é fundamental que os procedimentos realizados sejam ordenados por protocolos médico-sanitários que visem impedir ou minimizar os riscos inerentes à atividade. Diversos tipos de protocolos são adotados visando regular e regulamentar os serviços e os procedimentos realizados, tanto no atendimento direto da população quanto na manipulação de amostras em exames, no desenvolvimento e produção de medicamentos e em outras atividades que caracterizam o complexo.

Um dos campos de atuação da regulação e da regulamentação públicas está estabelecido sobre um conjunto de ocupações do complexo da saúde. Normalmente estas estão relacionadas a profissões, isto é, a qualificações adquiridas no processo de formação educacional formal e submetidas à extensa normatização do conhecimento teórico e prático incorporado. Ademais, é importante que se tenha presente que essas profissões cumprem papel central no atendimento de saúde.

A regulação e a regulamentação dessas ocupações ou profissões decorrem da necessidade de se reduzir os riscos que a atuação não baseada em protocolos carrega. Esta característica não é uma particularidade do complexo da saúde, sendo observada em vários campos do conhecimento. A exigência de formação específica para o engenheiro civil responsável por um projeto ou obra pode ser tomada como um exemplo. Porém, a necessidade de regulação e regulamentação da ocupação no complexo de saúde apresenta aspectos próprios, que não podem e nem devem ser considerados correlatos aos observados para ocupações de outras áreas de atuação profissional.

A irreversibilidade dos resultados oriundos da realização de determinados procedimentos de risco exige a adoção de protocolos estritos visando coibir ao máximo possíveis erros. Por exemplo, o risco de contaminação com sangue infectado pelo HIV impõe regras para uso do insumo em transfusão e para sua manipulação pelos profissionais pertencentes ou não ao segmento nuclear dessa atividade.

A realização de uma operação de catarata também deve seguir um protocolo, com o objetivo de impedir ou minimizar o risco de a atividade resultar em uma situação de cegueira para o paciente, que caso estabelecido tem alta probabilidade de não poder ser revertida. Enfim, seria possível dar diversos exemplos de risco potencial 
que, caso concretizado, a reversão do resultado não se apresenta como possível.

Neste sentido, a segmentação da estrutura ocupacional do complexo da saúde pode ser pensada como o esquema apresentado na Figura 1. Os três segmentos que organizam a estrutura ocupacional do complexo relacionam-se diferenciadamente com o mercado de trabalho. O segmento das ocupações nucleares tende a ser objeto de extensa regulação e regulamentação públicas, estando menos exposto aos mecanismos de oferta e demanda de força de trabalho. O segmento de ocupações afins também é, em geral, regulado e regulamentado, porém, não é especifico do setor saúde. Apesar da ocupação de químico ser regulamentada e estar presente na estrutura ocupacional do complexo, ela não tem nele sua área foco de atuação. Finalmente, encontra-se um segmento formado por diversas ocupações, em sua maioria não reguladas ou regulamentadas, que pertencem ao mercado de tra-

\begin{tabular}{|c|c|}
\hline Ocupações nucleares & \multicolumn{1}{|c|}{$\begin{array}{l}\text { Segmento ocupacional } \\
\text { do setor Saúde }\end{array}$} \\
\hline Ocupações afins & \\
\hline Demais ocupações & \\
\hline & \\
\hline
\end{tabular}

Figura 1. O segmento ocupacional do setor Saúde e o mercado geral de trabalho balho geral, mas que não apresentam formação ou especialização na área da saúde, como é o caso de motoristas, seguranças e atendentes.

Tais características da estrutura ocupacional do complexo da saúde impõem condições particulares no processo de contratação da força de trabalho, impedindo ou reduzindo as possibilidades de prevalecerem mecanismos característicos do mercado geral de trabalho. Ademais, por responder por parte importante da estrutura ocupacional e mesmo por sua regulação e regulamentação, o setor público acaba sendo determinante para a organização da estrutura ocupacional do complexo.

\section{A estrutura ocupacional \\ do complexo da saúde}

Ao longo deste ensaio trabalhou-se a perspectiva de se considerar a estrutura ocupacional do complexo da saúde de modo mais amplo, para além das ocupações clássicas, consideradas aqui como nucleares. Neste sentido, a preocupação do ensaio não se restringe à dimensão conformada pelas ocupações entendidas como recursos humanos específicos e que tem referência na atividade de atendimento direto à população. Esta perspectiva não visa minimizar a importância das ocupações nucleares, mas dar evidências da relevância do complexo para a mobilização do mercado de trabalho nacional e explicar a razão da elevada elasticidade do emprego que a condução da política de saúde carrega.

Anteriormente, foi apontada a importância da ocupação do complexo da saúde no mercado de trabalho nacional em 2009, bem como a extensão da ocupação de alguns outros complexos ou setores considerados fundamentais para o desempenho do produto e do nível de ocupação do país. Na Tabela 2, apresenta-se uma síntese da estrutura ocupacional do complexo e sua evolução entre 2003 e 2009.

Tabela 2. População ocupada do Complexo da Saúde - Brasil, 2003/2009

\begin{tabular}{llrr}
\hline & \multicolumn{1}{c}{$\mathbf{2 0 0 3}$} & $\mathbf{2 0 0 6}$ & \multicolumn{2}{c}{$\mathbf{2 0 0 9}$} \\
\hline Complexo da Saúde (A) & 3.526 .182 & 3.947 .293 & 4.472 .086 \\
Núcleo (B) & 1.815 .946 & 1.992 .442 & 2.425 .856 \\
População ocupada total (C) & 80.359 .109 & 88.725 .147 & 92.689 .253 \\
& & & \\
(B) / (A) & 51,5 & 50,5 & 54,2 \\
(A) / (C) & 4,4 & 4,4 & 4,8
\end{tabular}

Fonte: Pesquisa Nacional por Amostra Domiciliar, PNAD/IBGE. Microdados. Elaboração própria. 
De acordo com a estimativa, a ocupação do complexo da saúde ganhou expressão durante o período considerado, sendo que este incremento esteve relacionado com a expansão das ocupações nucleares. Isto é, as atividades e as ocupações nucleares cresceram mais rapidamente que o total do complexo, sinalizando que o atendimento da população deve ter se constituído no carro chefe da expansão de seu nível de ocupação. Em 2009, ao redor de 4,5 milhões de pessoas estavam ocupadas na saúde, sendo que $2,4 \mathrm{mi}$ lhões eram ocupações nucleares.

Apresentada a informação básica da extensão da ocupação do complexo de saúde no mercado de trabalho brasileiro, cabe agora explorar a sua estrutura de ocupação propriamente dita. $\mathrm{Na}$ Tabela 3, é possível conhecer a distribuição da ocupação segundo segmentos de atividade e ocupações. Os resultados mostram uma dominância das atividades fundamental e de administração pública e das ocupações nucleares na estrutura de emprego, sinalizando que o crescimento desta dimensão ocupacional tende a afetar a ocupação do complexo como um todo, pois boa parte das ocupações afins e demais pertencem às atividades fundamental e de administração pública. A área cinza delimita a dimensão da ocupação e das atividades consideradas diretamente vinculadas ao atendimento à saúde da população.
A presença da administração pública destacada da atividade fundamental deve-se à classificação de unidades de saúde vinculadas a órgãos públicos como ministérios e universidades. Essas unidades não são identificadas no setor de atendimento à saúde que organiza os estabelecimentos hospitalares, os postos de saúde e as clínicas.

De acordo ainda com os resultados compilados na Tabela 3, é possível avaliar a importância da ocupação do setor privado no complexo da saúde. Em 2009, ele representava, aproximadamente, $38 \%$ da ocupação total do complexo e $28 \%$ do seu núcleo. Quando consideradas somente as ocupações do segmento de atividade fundamental, nota-se que a participação do setor privado alcança 47\%. Entretanto, verifica-se que o setor tem relativamente maior relevância nas ocupações afins e demais ocupações e significativamente menor nas ocupações do núcleo.

A razão deste resultado decorre da maior expressão do trabalho em clínicas e laboratórios que se encontram sob responsabilidade do setor privado, cabendo ao setor público um peso maior nas atividades fins, seja dos hospitais ou da rede de atenção primária. O resultado revela, prontamente, a importância do setor público na estrutura ocupacional do complexo da saúde. Apesar da reconhecida expansão do setor privado, estimulada pelo crescimento rápido dos pla-

Tabela 3. Estrutura de rendimento da população ocupada do Complexo da Saúde - Brasil, 2009

\begin{tabular}{|c|c|c|c|c|}
\hline \multirow{2}{*}{ Segmentos } & \multicolumn{4}{|c|}{ Segmentos } \\
\hline & Núcleo & Afins & Demais ocupações & Total \\
\hline & \multicolumn{4}{|c|}{ População ocupada } \\
\hline Fundamentais & 1.748 .813 & 32.976 & 1.094 .774 & 2.876 .563 \\
\hline Adm. Pública & 486.564 & 92.027 & 414.221 & 992.812 \\
\hline Complementares & $2 \underline{5} .67 \underline{4}$ & 39.802 & 46.875 & 112.351 \\
\hline Apoio & 153.899 & 184.049 & & 337.948 \\
\hline Demais setores & 152.411 & & & 152.411 \\
\hline Complexo Saúde (A) & 2.567 .361 & 348.854 & 1.555 .871 & 4.472 .086 \\
\hline Complexo Saúde - Núcleo & - & - & & 2.425 .856 \\
\hline População ocupada (B) & & & & 92.689 .253 \\
\hline \multirow[t]{2}{*}{ (A) / (B) } & - & - & & 4,8 \\
\hline & \multicolumn{4}{|c|}{ Participação do Setor privado (\%) } \\
\hline Fundamentais & 36,7 & 44,0 & 64,5 & 47,4 \\
\hline Adm. Pública & - & - & - & - \\
\hline Complementares & 29,1 & 27,5 & 50,3 & 37,4 \\
\hline Apoio & $6 \overline{2}, \overline{7}$ & 36,2 & & 48,3 \\
\hline Demais setores & 75,4 & & 46,9 & 75,4 \\
\hline Complexo Saúde (A) & 33,5 & 26,4 & & 37,6 \\
\hline Complexo Saúde - Núcleo & & & & 27,8 \\
\hline
\end{tabular}

Fonte: Pesquisa Nacional por Amostra Domiciliar, PNAD/IBGE. Microdados. Elaboração própria. 
nos coletivos de saúde, constata-se que o setor público responde por duas de cada três ocupações nucleares. Tal resultado sugere ser o gasto público decisivo para a cobertura do serviço de atendimento e, também, para sua qualidade, que fundamentalmente depende da qualificação e da quantidade de profissionais próprios da atividade fim do complexo. Ao contrário do sugerido exaustivamente pela imprensa, os dados demonstram a centralidade do setor público para a estruturação das atividades nucleares.

\section{A qualificação da estrutura ocupacional}

A análise do perfil de qualificação formal dos ocupados do complexo da saúde, que se expressa pela média de anos de estudos prevalecente em sua estrutura ocupacional, aponta para uma situação relativamente mais favorável àquela observada para o mercado de trabalho. Nota-se, ademais, que o indicador vem apresentando uma tendência de elevação. Nas ocupações nucleares, a média aproxima-se de 14 anos de estudos.

A regulação e a regulamentação exercidas sobre as ocupações nucleares tendem a determinar uma média elevada. Deve-se reconhecer, ademais, a exigência sistêmica de atualização e aprimoramento do conhecimento para a atuação na atividade de atendimento à saúde, que tende a provocar uma elevação recorrente da média de anos de estudo. Estas características revelam que a expansão dos serviços do complexo tende a ter uma elasticidade do emprego elevada, como já apontado anteriormente, mas também deve ser um fator que contribui para a elevação do perfil de qualificação do mercado de trabalho nacional.

Este é um aspecto da ocupação setorial pouco explorado nos estudos, o que minimiza tanto sua contribuição para a atividade do complexo da saúde, quanto para o perfil de qualificação do mercado nacional de trabalho.

É amplamente reconhecida a necessidade de elevação do perfil de qualificação da estrutura ocupacional brasileira, como um dos elementos para alteração das condições de produtividade e do padrão de remuneração prevalecente no mercado de trabalho. Em geral, são apontados como relevantes alguns segmentos em que prepondera a atividade econômica privada, como os complexos automobilístico e bancário-financeiro. $\mathrm{Ne}$ nhuma atenção é dada para segmentos com ampla presença do setor público. Normalmente, estes segmentos são vistos em uma perspectiva negativa, seja em razão da baixa produtividade ne- les prevalecentes, seja pelo suposto gasto elevado em que incorrem.

A análise do trabalho do complexo da saúde apresenta informações relevantes para uma alteração deste enfoque que desvaloriza seu papel no mercado nacional de trabalho. A importância do complexo da saúde para o bem-estar da população é inegável, mesmo considerando que sua contribuição necessite ter melhor qualidade e abrangência. A melhoria dos indicadores de saúde favorece as condições de vida da população brasileira, bem como a atividade econômica. Uma pessoa em boas condições de saúde apresenta uma característica fundamental e decisiva para contribuição produtiva do trabalho. Ademais, a qualidade da política de saúde depende, dentre outros determinantes, da qualificação da força de trabalho envolvida.

Os resultados apontam que esta força de trabalho apresenta um perfil de educação superior à média do mercado de trabalho, sinalizando, portanto, que os investimentos em qualificação da força de trabalho no complexo da saúde têm o potencial de influir positivamente a estrutura ocupacional brasileira. Nesse sentido os gastos com pessoal do complexo devem ser considerados como um investimento, ao favorecer tanto o bemestar da população quanto a estrutura ocupacional do mercado nacional de trabalho (Gráfico 1).

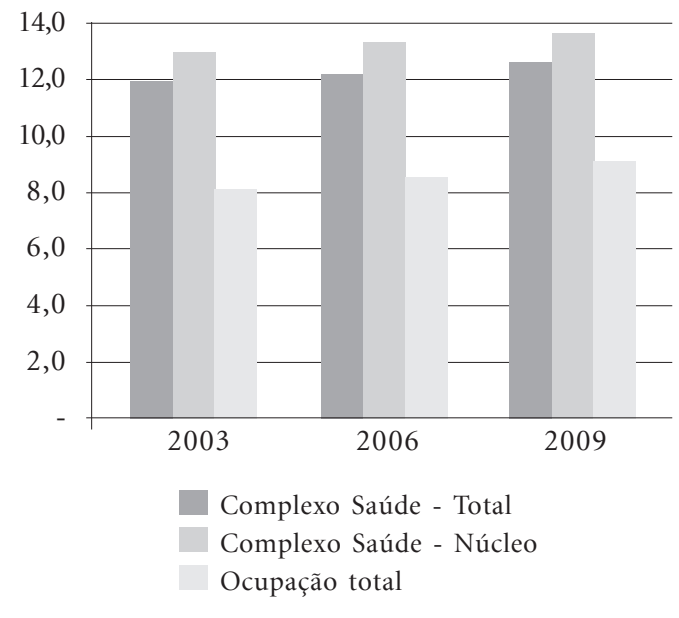

Gráfico 1. Número de anos de estudo da população ocupada total e dos ocupados do Complexo da Saúde - Brasil, 2003/2009

Fonte: Pesquisa Nacional por Amostra Domiciliar, PNAD/ IBGE. Microdados. Elaboração própria. 
Estes argumentos exigem uma requalificação do modo como se avalia o trabalho, na medida em que sua apreciação não pode estar circunscrita à dimensão estabelecida pelo que tradicionalmente se chama de recursos humanos específicos. O trabalho no complexo é relevante para seus objetivos fins, mas também se apresenta como uma peça importante para o mercado de trabalho, seja por ser um segmento qualificado, seja por contribuir positivamente para o perfil da estrutura ocupacional brasileira.

\section{O padrão de rendimentos da estrutura ocupacional}

Os dados de remuneração reforçam esta perspectiva. De acordo com a Tabela 4, a média de rendimento do complexo da saúde é $47 \%$ superior à média do mercado de trabalho. $\mathrm{O}$ conjunto de ocupações de menor remuneração do com- plexo é semelhante a esta última referência. Desse modo, uma elevação da participação da ocupação do complexo tende a ter um duplo impacto positivo sobre o mercado de trabalho, em termos de qualificação e de remuneração.

No entanto, quando analisados os rendimentos dos ocupados na saúde, constata-se que sua evolução foi inferior à observada para o total da população ocupada, reiterando tendência já observada ao longo da década de 1990. Se, de um lado a situação relativa dos rendimentos do complexo apresenta-se como favorável para o mercado de trabalho, de outro sua evolução mostra-se preocupante, em especial devido à tendência de crescente fragmentação da estrutura dos contratos e das relações de trabalho ${ }^{18}$. Tal processo também é reconhecido pelo próprio Ministério da Saúde ${ }^{19}$. Essa situação não pode ser imputada ao setor público que, como evidenciado pelos resultados da Tabela 4 , tende a remunerar, em média, melhor que o setor privado, par-

Tabela 4. Estrutura de rendimento da população ocupada do Complexo da Saúde - Brasil, 2003/2009

\begin{tabular}{|c|c|c|c|c|}
\hline \multirow{2}{*}{ Segmentos } & \multicolumn{4}{|c|}{ Segmentos } \\
\hline & Núcleo & Afins & Demais ocupações & Total \\
\hline & \multicolumn{4}{|c|}{ Rendimento em $2009^{*}$} \\
\hline Fundamentais & 2.174 & 1.668 & 998 & 1.716 \\
\hline Adm. Pública & 1.311 & 1.511 & & 1.604 \\
\hline Complementares & 2.291 & 1.189 & & 1.307 \\
\hline Apoio & 1.473 & 742 & & 1.163 \\
\hline Demais setores & 1.578 & & & 992 \\
\hline Complexo Saúde & 1.929 & 579 & & 1.558 \\
\hline Complexo Saúde - Núcleo & & & & 1.954 \\
\hline \multirow[t]{2}{*}{ População ocupada } & & & & 1.062 \\
\hline & \multicolumn{4}{|c|}{ Evolução rendimento real $(2003=1)$} \\
\hline Fundamentais & 1,09 & 1,06 & 1,03 & 1,10 \\
\hline Adm. Pública & 1,41 & 1,48 & & 1,35 \\
\hline Complementares & 1,51 & 1,17 & & 1,23 \\
\hline Apoio & 1,25 & 1,50 & & 1,19 \\
\hline Demais setores & 1,22 & & & 1,19 \\
\hline Complexo Saúde & 1,14 & 1,17 & & 1,13 \\
\hline Complexo Saúde - Núcleo & & & & 1,13 \\
\hline \multirow[t]{2}{*}{ População ocupada } & & & & 1,20 \\
\hline & \multicolumn{4}{|c|}{ Setor público/Setor privado } \\
\hline Fundamentais & 1,2 & 1,5 & 1,1 & 1,3 \\
\hline Adm. Pública & 0,7 & 0,8 & & 1,3 \\
\hline Complementares & 1,6 & 1,2 & & 1,0 \\
\hline Apoio & 0,6 & 1,1 & & 0,6 \\
\hline Demais setores & 2,1 & & & 2,5 \\
\hline Complexo Saúde & 1,1 & 1,4 & & 1,2 \\
\hline Complexo Saúde - Núcleo & & & & 1,0 \\
\hline
\end{tabular}

Fonte: Pesquisa Nacional por Amostra Domiciliar, PNAD/IBGE. Microdados. Elaboração própria.

* valores a preços de 2009. Deflator: INPC. 
ticularmente nas atividades e ocupações de maior relevância para o complexo. Os resultados sugerem que as dificuldades em termos de remuneração estão associadas ao complexo como um todo, não podendo ser relacionadas ao setor público ou ao privado.

As remunerações do setor público encontram-se condicionadas à situação fiscal dos entes federativos e também às suas estruturas ocupacionais. Quanto à remuneração auferida pelo pessoal ocupado no setor privado, a crescente subordinação dos serviços de atendimento aos planos e/ou seguros de saúde tende a estabelecer restrições a sua evolução. Em suma, é razoável afirmar-se que os ganhos de remuneração propiciados pela regulação pública do mercado de trabalho ou pela negociação coletiva tendem a ser mais limitados no interior da estrutura ocupacional do complexo da saúde.

Nesse sentido, a heterogeneidade das formas de contrato e relações de trabalho prevalecente no complexo tende a reiterar as restrições a uma trajetória mais favorável de seu padrão de remunerações, bem como de sua contribuição para o mercado de trabalho como um todo.

\section{Considerações Finais: os desafios para o complexo da saúde e sua força de trabalho}

O percurso analítico realizado neste ensaio explicita algumas das vantagens que o complexo da saúde aporta para o mercado de trabalho brasileiro, bem como as restrições por ele conhecidas em termos de poupança de trabalho, em geral decorrentes do aumento da escala da prestação dos serviços e da incorporação da disponibilidade tecnológica setorial. Tais restrições tornam-se ainda mais rígidas quando o complexo tem sua referência no atendimento de baixa complexidade, como ocorre na experiência brasileira.

A estruturação da política a partir do Programa Saúde da Família demanda a constituição de milhares de equipes multiprofissionais, visando prevenir e orientar as famílias, muitas vezes atendidas em seus domicílios. A extensa dimensão territorial e a heterogeneidade regional, que marcam o país, impactam sobre o desempenho dessas equipes. Enquanto uma equipe localizada em uma comunidade na periferia de uma grande metrópole pode visitar diversas famílias em único dia, constata-se que outra equipe situada no sertão nordestino ou na região amazônica tem capacidade de atendimento diário de poucas unidades familiares. Seja no Sudeste como no Nor- deste ou no Norte do país, o atendimento à saúde das famílias tem como elemento predominante a força de trabalho dos profissionais das equipes, que lançam mão de equipamentos básicos com reduzido conteúdo tecnológico.

Como apontado anteriormente, a expansão do complexo da saúde tende a carregar uma elevada elasticidade do emprego ao ampliar sua cobertura. No entanto, ficou evidente que ela não tem sido acompanhada da ampliação dos recursos financeiros necessários. Ademais, a necessidade de se aumentar a cobertura do atendimento de saúde encontrou uma restrição adicional imposta pela implantação de outros instrumentos da política social determinados pela Constituição Federal de 1988, em um contexto de semiestagnação econômica do período 1990-2003 ${ }^{17,20-}$ 22. A insuficiência de recursos é comum a todas as políticas sociais, o que se traduz em uma disputa feroz entre elas pelos recursos disponíveis. É fundamental que se defenda que o SUS esteja articulado às demais vertentes da política social e que os recursos sejam adequados de forma a contemplar a totalidade dessas ações.

Portanto, a importância do quadro institucional da política social brasileira exige o encaminhamento de um orçamento global apropriado, em que sejam equacionadas tanto as necessidades de recursos do SUS quanto a regulação da atuação do setor privado ${ }^{17}$.

Destaca-se que a expansão do atendimento à saúde conheceu um duplo movimento: além de a ampliação da cobertura do serviço prestado pela esfera pública ter sido acompanhada por uma progressiva deterioração de sua qualidade, o crescimento da atenção à saúde prestada pelo setor privado também sofreu em termos de qualidade. Este processo tem estado atrelado a uma trajetória desfavorável dos rendimentos da população até 2003 e a capacidade reduzida de remuneração dos planos de saúde. Como evidenciou a pesquisa realizada pelo Instituto de Economia da Unicamp para o Ministério da Saúde ${ }^{10}$, esse duplo movimento acabou por traduzir-se na consolidação de um complexo da saúde cada vez mais importante nos âmbitos econômico e social. No entanto, evidenciou-se uma recorrente deterioração das condições de trabalho, tanto nas atividades fins como nas complementares.

Uma das características desse processo tem sido a crescente heterogeneidade das formas de contrato de trabalho, bem como a elevação do grau de instabilidade a eles inerente ${ }^{10}$. Esse resultado decorre, também, de uma maior heterogeneidade das figuras institucionais como as coo- 
perativas de trabalho, as organizações da sociedade civil de interesse público, as organizações não governamentais e as fundações privadas, que realizam os serviços de atendimento.

$\mathrm{O}$ ambiente de restrição de recursos para a política de saúde, muitas vezes caracterizada pela irregularidade dos repasses e liberação pelas esferas de governo, por um lado, estimulou o crescimento dessas novas formas institucionais, mas por outro, produziu uma deterioração progressiva dos contratos e das relações de trabalho do complexo.

Essa tendência tem se constituído em um movimento comum a outros países ${ }^{23-26}$. Nos desenvolvidos, o envelhecimento da estrutura ocupacional tem gerado um aumento substantivo da demanda de serviços de atendimento à saúde, a qual tem sido caracterizada pela necessidade de implantação de novas modalidades. Essa pressão também recai sobre a previdência social, fa- zendo com que as demandas por novos recursos dessas duas políticas evoluam em ritmo mais acelerado ao observado para disponibilidade fiscal dos governos. Nos países em desenvolvimento, a demanda por aumentos da cobertura e da qualidade do atendimento à saúde articula-se às demandas por acesso à educação, água e saneamento, habitação, dentre outras. Isso torna a disputa por recursos muito mais acentuada, especialmente quando se considera a ausência de crescimento que atingiu esses países ao longo dos anos 1980 e 1990.

Portanto, defende-se que, para o Brasil alcançar uma alteração positiva e estrutural no complexo da saúde, é necessário que a política setorial não se dissocie das políticas sociais, contemplando a complexidade exigida pela universalização e não promovendo a disputa selvagem por recursos entre elas, diminuindo assim os problemas associados a essa repartição orçamentária.

\section{Colaboradores}

CS Dedecca e CJBM Trovão participaram igualmente de todas as etapas de elaboração do artigo. 


\section{Referências}

1. Brasil. Emenda Constitucional n ${ }^{\circ} 29$, de 13 de setembro de 2000. Altera os arts. 34, 35, 156, 160, 167 e 198 da Constituição Federal e acrescenta artigo ao Ato das Disposições Constitucionais Transitórias, para assegurar os recursos mínimos para o financiamento das ações e serviços públicos de saúde. Diário Oficial da União 2000; 14 set.

2. Brasil. Lei no 9.311, de 24 de outubro de 1996. Institui a Contribuição Provisória sobre Movimentação ou Transmissão de Valores e de Créditos e Direitos de Natureza Financeira - CPMF, e dá outras providências. Diário Oficial da União 25/10/1996; 25 out.

3. Dedecca CS. A importância e a complexidade da política de saúde e do desenvolvimento nacional com justiça social. Jornal do Economista 2012; 270:3-4.

4. Costa NR. Inovação Política, Distributivismo e Crise: A Política de Saúde nos Anos 80 e 90. Revista Dados 1996; 39(3).

5. Campos FE, Albuquerque EM. As especificidades contemporâneas do trabalho no setor saúde: notas introdutórias para uma discussão. Belo Horizonte: Cedeplar, UFMG; 1998. [Texto para Discussão, n. 123]

6. Gadelha CAG. O complexo industrial da saúde e a necessidade de um enfoque dinâmico na economia da saúde. Cien Saude Colet 2003; 8(2):521-535.

7. Silva LMO. Organização e relações de trabalho no setor de serviços de saúde no Brasil [dissertação]. Campinas (SP): Unicamp; 2006.

8. Arrow KJ. Uncertainty and the welfare economics of medical care. American Economic Review 1963; 53(5):141-149.

9. Brasil. Ministério da Saúde (MS). Instituto de Economia. Unicamp. O Setor Saúde e a Geração de Empregos [relatório de Pesquisa]. Campinas: Fundação Economia de Campinas; 2005. (Contrato Administrativo, N.10046/2002)

10. Dedecca CS. O Trabalho no Setor Saúde. São Paulo em Perspectiva 2008; 22(2):87-103.

11. Girardi SN, Carvalho CL, Girardi Júnior JB, Araújo JF. Configurações do mercado de trabalho dos assalariados em saúde no Brasil. In: Barros AFR, Santana JP, Santos Neto PM. Observatório de Recursos Humanos em Saúde no Brasil: Estudos e Análises. Vol. 2. Rio de Janeiro: Fiocruz; 2004.

12. Brasil. Ministério da Saúde (MS). Departamento de Gestão e da Regulação do Trabalho em Saúde. Secretaria de Gestão do Trabalho e da Educação na Saúde. In: Seminário Nacional sobre Política de Desprecarização das Relações de Trabalho no SUS; 2003; Brasília, MS.

13. Brasil. Lei $n^{\circ} 8.080$, de 19 de setembro de 1990 . Dispõe sobre as condições para a promoção, proteção e recuperação da saúde, a organização e o funcionamento dos serviços correspondentes e dá outras providências. Diário Oficial da União 1990; 20 set.

14. Brasil. Ministério do Desenvolvimento Social e Combate à Fome. Secretaria Nacional de Assistência Social. Norma Operacional Básica de Recursos Humanos do SUAS - NOB-RH/SUAS. 2006. [site da internet]. [acessado 2013 abr 23]. Disponível em: http://www.mds.gov.br/assistenciasocial/publicacoes-para-impressao-em-grafica/norma-operacionalbasica-de-recursos-humanos-do-suas-nob-rh-suas
15. Organisation for Economic Co-operation and Development (OECD). Health at a Glance. OECD Indicators, OECD Publishing, 2011. [site da internet]. [acessado 2013 abr 23]. Disponível em: http://www.oecdilibrary.org/social-issues- migration-health/health-ata-glance-2011_health_glance-2011-en

16. Silva SF. Medicina social e gestão pública - da teoria à prática. Revista RADIS - Comunicação em Saúde 2005; (34):19.

17. Instituto de Pesquisa Econômica Aplicada (IPEA). Introdução: Perspectivas Abertas à Política Social no Brasil. In: Instituto de Pesquisa Econômica Aplicada (IPEA). Perspectivas da política social no Brasil. Livro 8. Brasília: IPEA; 2010. p. 13-21.

18. Andreazzi MFS. Formas de remuneração de serviços de saúde. Brasília: IPEA; 2003. [Texto para Discussão, n. 1006]

19. Brasil. Ministério da Saúde (MS). Secretaria de Gestão do Trabalho e da Educação na Saúde. Relatório do Seminário Nacional sobre Politica de Desprecarização das Relações de Trabalho no SUS. Brasília: MS; 2003.

20. Piola SF, Barros ED, Nogueira RP, Servo LM, Batista de Sá E, Paiva AB. Vinte anos da Constituição de 1988: o que significaram para a população brasileira? Boletim de Politicas Sociais 2009; 17(1):97-174.

21. Dain S. Os impasses do financiamento do SUS. Trab Educ Saúde 2009; 6(3):623-632.

22. Associação Nacional dos Auditores Fiscais da Receita Federal do Brasil (ANFIP). Análise da Seguridade Social 2011. Brasília: ANFIP; 2012.

23. Quinlan M, Mayhew C, Bohle P. The global expansion of precarious employment, work disorganisation and occupational health, a review of recent research. Int I Health Serv 2001; 31(2):335-414.

24. Homedes N, Ugalde A. Human resources: the Cinderella of health sector reform in Latin America. Hum Resour Health 2005; 3:1.

25. Benach J, Muntane C. Precarious employment and health: developing a research agenda. J Epidemiol Community Health 2007; 61(4):276-277.

26. Armstrong P, Armstrong H. Precarious Employment in the Health-Care Sector. In: Vosko LF, MacDonald M, Campbell I, editors. Gender and the Contours of Precarious Employment. New York: Routledge Press; 2009.

Artigo apresentado em 20/09/2012

Aprovado em 30/11/2012

Versão final apresentada em 17/12/2012 
